\title{
Correction to: Granular computing in mosaicing of images from capsule endoscopy
}

\author{
Lukasz Maciura $^{1} \cdot$ Jan G. Bazan ${ }^{2}$
}

Published online: 2 January 2019

(C) The Author(s) 2019

\section{Correction to: Nat Comput (2015) 14:569-577 https://doi.org/10.1007/s11047-014-9477-y}

In the original publication, Acknowledgments was published incorrectly. The correct Acknowledgments is provided in this correction.

Acknowledgements This work was partially supported by the Centre for Innovation and Transfer of Natural Sciences and Engineering Knowledge of University of Rzeszów, Poland.

Open Access This article is distributed under the terms of the Creative Commons Attribution License which permits any use, distribution, and reproduction in any medium, provided the original author(s) and the source are credited.

The original article can be found online at https:// doi.org/10.1007/s11047-014-9477-y.

Lukasz Maciura

lmaciura@ur.edu.pl

1 Chair of Computer Science, University of Rzeszów, Pigonia 1, 35-310 Rzeszów, Poland

2 Interdisciplinary Centre for Computational Modelling, University of Rzeszów, Pigonia 1, 35-310 Rzeszów, Poland 